\title{
Prevention of Rh Immunization Due to Large Volumes of Rh-positive Blood
}

\author{
J. C. WOODROW,* M.D., M.R.C.P.; C. C. BOWLEY, † M.B., B.S., M.R.C.o.G. \\ B. E. GILLIVER, $\ddagger$ M.B., B.S.; S. J. STRONG,§ M.B., D.R.C.O.G., D.PATH.
}

Brit. med. F., 1968, 1, 148-150

It has recently been shown that it is possible to prevent $\mathrm{Rh}$ negative individuals from being immunized by $\mathrm{Rh}$-positive blood. This was first established under experimental conditions in which Rh-negative male volunteers were injected with $5 \mathrm{ml}$. of $\mathrm{Rh}$-positive blood and then given $50 \mathrm{ml}$. of plasma containing incomplete anti-D (Finn et al., 1961 ; Clarke et al., 1963). This method was then applied in a clinical trial in which the subjects were Rh-negative primiparae just delivered of an $\mathrm{ABO}$ compatible Rh-positive child and had $0.25 \mathrm{ml}$. or more of circulating foetal blood after delivery (Woodrow et al., 1965; B.M.F., 1966). In the trial $5 \mathrm{ml}$. of gammaglobulin containing approximately $1,000 \mu \mathrm{g}$. of anti-D was injected intramuscularly within 36 hours of delivery. The results convincingly demonstrated that anti-D formation by the mothers was prevented, and it appears likely that this treatment will prove to be a practical method of preventing $\mathrm{Rh}$-haemolytic disease of the newborn.

It remains to be determined what constitutes an appropriate dose of gammaglobulin and whether this needs to be varied in different cases. It has been shown that there is a direct relation between the number of $\mathrm{Rh}$-positive foetal cells in the maternal circulation after delivery and the risk of subsequent immunization (Woodrow et al., 1965), but this may only hold up to a certain volume of $\mathrm{Rh}$-positive blood (see below). In most cases the volumes of foetal blood involved are quite small. Thus an analysis of foetal cell counts carried out in Liverpool on 701 primiparae just after the delivery of $\mathrm{ABO}$ compatible babies showed that no foetal blood was found in 333 cases, up to $1 \mathrm{ml}$. was found in $330,1-5 \mathrm{ml}$. in $32,5-20 \mathrm{ml}$. in four, and more than $20 \mathrm{ml}$. in two. Further work since the first clinical trial makes it seem likely that in the great majority of $\mathrm{Rh}$-negative women the prevention of immunization as a result of pregnancy can be effected by the injection of $1 \mathrm{ml}$. of gammaglobulin, representing about $200 \mu \mathrm{g}$. of anti-D (Clarke et al., 1966; Clarke, 1967). However, in approximately one in 300 deliveries a considerable transplacental haemorrhage of the order of 100$170 \mathrm{ml}$. occurs, and it is not known what dosage of gammaglobulin would be effective in preventing immunization in such cases. A similar situation exists in the case of mistransfusion of Rh-negative patients with Rh-positive blood.

Four Rh-negative patients have been observed who received considerable volumes of $\mathrm{Rh}$-positive blood, and each was treated

- Nuffield Unit of Medical Genetics, Department of Medicine, University of Liverpool.

† Director, Regional Transfusion Centre, Sheffield.

$\neq$ County Laboratory, Dorchester.

$\checkmark$ Radcliffe Infirmary, Oxford. with a view to preventing $\mathrm{Rh}$-antibody formation. The results of these attempts are described.

\section{The Four Cases}

Details of the cases are given in the Table, and in the Chart is shown the estimated survival of the Rh-positive blood in each patient. In Cases 1 and 2 the survival was determined by serial estimations of the ratios of foetal to maternal cells by means of the acid elution technique (Kleihauer and Betke, 1960). In Cases 3 and 4 the number of surviving cells was determined by the Ashby differential agglutination technique. There are probably differences between the sensitivities of these two methods.

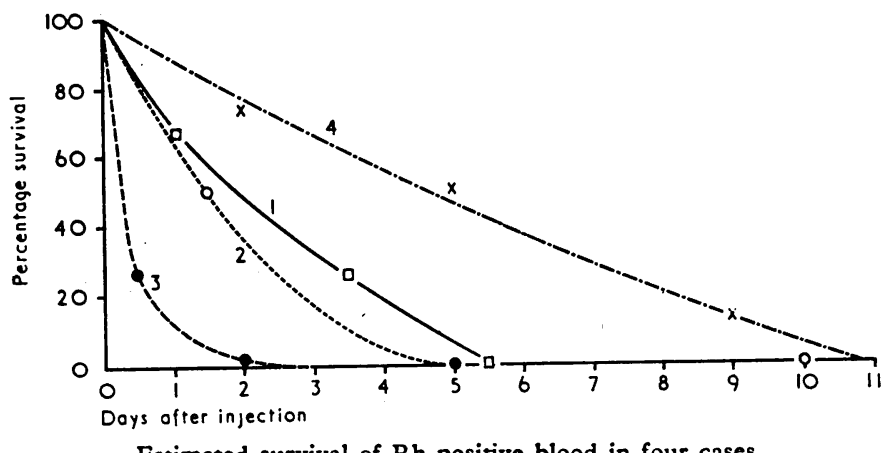

Estimated survival of $\mathrm{Rh}$-positive blood in four cases.

Case 1.-A primigravida, blood group A Rh-negative, was delivered of an A Rh-positive child, and at birth the baby had a haemoglobin of $9.3 \mathrm{~g} . / 100 \mathrm{ml}$. The ratio of foetal to adult cells in the maternal blood was approximately $1: 30$, suggesting a transplacental haemorrhage of $170 \mathrm{ml}$. of foetal blood. Thirty hours after delivery $5 \mathrm{ml}$. of anti-D gammaglobulin was given. Twentyfour hours after this injection it was estimated that $34 \%$ of the $\mathrm{Rh}$ positive blood had been cleared, and that after 84 hours clearance had risen to $74 \%$. After 135 hours the surviving Rh-positive foetal blood was estimated at approximately $0.1 \mathrm{ml}$. A curious finding was that the direct Coombs test was negative on the 24-hour sample but positive on the 84-hour sample. Moreover, free antibody in the plasma was not detected until the 135-hour sample. It is difficult to explain these findings. Samples of blood obtained four and six months after delivery showed no antibody.

Case 2.'-A primigravida, blood group A Rh-negative, showed evidence of about $170 \mathrm{ml}$. of circulating foetal blood after the

' This case was reported in a letter to the Brit. med. F., 1967, 3, 47.

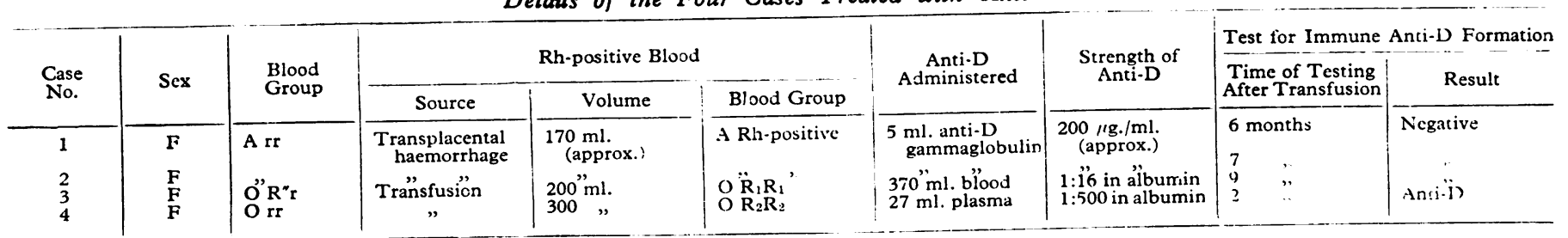


delivery of an anaemic infant (haemoglobin $8.0 \mathrm{~g} . / 100 \mathrm{ml}$.). The baby was A Rh-positive and the direct Coombs test was negative. Seventy-two hours after delivery $5 \mathrm{ml}$. of anti-D gammaglobulin was given intramuscularly. Approximately $50 \%$ of the foetal cells were cleared during the subsequent 36 hours and the direct Coombs test was positive. Free antibody was present in the serum. The next sample, 10 days after injection, showed that approximately $0.2 \mathrm{ml}$. of foetal blood remained. Samples of blood taken three and seven months after delivery were free of antibody.

Case 3.-A primigravida of genotype $R^{\prime \prime} r$ suffered a post-partum haemorrhage and was transfused in error with $200 \mathrm{ml}$. of Rh-positive $\left(R_{1} R_{1}\right)$ blood. Two days later $370 \mathrm{ml}$. of blood from an immunized $\mathrm{Rh}$-negative donor was transfused intravenously. The plasma contained incomplete anti-D with a titre in albumin of 1:16. Two days after the infusion of anti-D it was estimated that only $2 \%$ of the transfused $\mathrm{Rh}$-positive blood had survived, but none could be detected on the fifth day. Free anti-D was detected in all the samples taken up to five days after the anti-D was given. Samples taken three and nine months after delivery were free of antibody.

Case 4.-This patient, who was group $\mathrm{O} R \mathrm{R}$-negative, received $300 \mathrm{ml}$. of $R_{2} R_{2}$ blood as a transfusion. The next day $13 \mathrm{ml}$. of serum containing incomplete anti-D with a titre of $1: 500$ in albumin was injected intravenously, and a day later a further $14 \mathrm{ml}$. of this serum was given. Nine days after the second injection of serum about $12 \%$ of the transfused blood had survived. A sample of blood taken two months after the injection of anti-D showed immune anti-D. In this case serum haptoglobin levels were measured, the level falling to zero five days after the second injection of serum and remaining low for over a week before returning to normal.

\section{Reactions}

In Cases 1, 2, and 4 no reactions were noted. Case 2 was tested for haemoglobinuria 36 hours after the anti-D was given and none was found. In Case 3 the transfusion of blood containing anti-D was given very slowly while the patient was carefully observed. When she had received $370 \mathrm{ml}$. of blood she began to shiver vigorously and the transfusion was stopped. The symptoms abated within minutes, and no other features of a transfusion reaction developed.

\section{Discussion}

Assessment of these observations must depend on a knowledge of the likelihood of immunization resulting from the transfusion of the volumes of $\mathrm{Rh}$-positive blood involved. There can be no certainty that the three patients who have not developed $\mathrm{Rh}$ antibody would have done so had they not been passively immunized. Pickles (quoted by Mollison, 1967) found Rh antibody in only 30 out of $60 \mathrm{Rh}$-negative subjects who had received a "single transfusion" of Rh-positive blood. Freda et al. (1964) found that $10 \mathrm{ml}$. of $\mathrm{Rh}$-positive blood induced the formation of anti-D in 6 out of 13 male volunteers. In a survey being carried out in Liverpool $10 \mathrm{Rh}$-negative primiparae were observed who had at least $3 \mathrm{ml}$. of circulating $\mathrm{Rh}$-positive foetal blood after delivery (the mean volume being $5 \mathrm{ml}$.), and of these, four developed anti-D during the ensuing six months. It may be that though a fairly close relation exists between the volume of $\mathrm{Rh}$-positive blood and the risk of immunization over the lower range of volume, the risk may not appreciably increase much above $50 \%$ as the volume rises over the $5-10 \mathrm{ml}$. range.

It would thus seem likely that at least half of the individuals receiving volumes of $\mathrm{Rh}$-positive blood of the order described here can be expected to develop anti-D, and it is encouraging that the three patients who were given considerable amounts of anti-D were not immunized. Nor is it perhaps surprising that one patient (Case 4) who received $300 \mathrm{ml}$. of blood and only $27 \mathrm{ml}$. of serum did develop immune anti-D. This patient was treated in 1964, when very little was known about the requirements of anti-D used in this way. Moreover, the transfused blood was of genotype $R_{2} R_{2}$, which provides a very strong antigenic stimulus. It is difficult to relate a dose of anti-D in the form of serum obtained from a single donor to that in the form of gammaglobulin obtained from a pool of hyperimmunized volunteers, yet it is probable that the $248 \mathrm{ml}$. of plasma given in Case 3 is roughly the equivalent of $12 \mathrm{ml}$. of gammaglobulin, and that the $27 \mathrm{ml}$. of plasma given in Case 4 is equivalent to about $1.5 \mathrm{ml}$. of gammaglobulin. It should be noted that in the latter case clearance of the Rh-positive blood was slow (see Chart).

The volumes of $\mathrm{Rh}$-positive blood involved in Cases 1 and 2 represent the greatest volume of transplacental haemorrhage likely to be encountered in practice, and the fact that these two patients did not develop anti-D supports the opinion that approximately $1,000 \mu \mathrm{g}$. of gammaglobulin may represent the highest protective dose likely to be needed in the prevention of $\mathrm{Rh}$-immunization due to pregnancy.

\section{Application to $\mathbf{R h}$-incompatible Transfusions}

It is worth while considering the application of this method to cases in which $\mathrm{Rh}$-negative women have been transfused in error with $\mathrm{Rh}$-positive blood before or during the child-bearing period. It seems likely that by administering a sufficient amount of incomplete anti-D they can be prevented from developing immune anti-D. The use of gammaglobulin preparations of anti-D has advantages over the use of plasma intravenously. They are obtained from the pooled plasma of several hyperimmunized donors and contain a high concentration of anti-D of marked avidity. There is virtually no risk of producing hepatitis. Absorption is relatively slow, resulting in a comparatively slow rate of red cell destruction. It is likely that the risk of transfusion reactions is thereby diminished.

The volumes of $\mathrm{Rh}$-positive blood transfused in these cases are, however, likely to be greatly in excess of those seen as a result of transplacental haemorrhage. A factor of great importance is the risk of renal damage. It is known that considerable haemoglobinaemia can occur when a non-lytic incomplete anti-D removes $\mathrm{Rh}$-positive blood from the circulation and destruction of the cells is predominantly extravascular (Jandl et al., 1957 ; Mollison, 1967). The relation of haemoglobinuria to the renal damage which may occur with incompatible transfusions remains uncertain. Mollison (1967) points out that such an eventuality is much more likely to occur where destruction of red cells is intravascular, and suggests that some other factor, possibly resulting in impaired renal blood flow, must be present in these cases.

Instances have been described of haemolytic transfusion reactions, associated with haemoglobinuria and oliguria and attributed to $\mathrm{Rh}$ antibodies, but as a rule a detailed knowledge of the serological status of the patients is lacking. Vogel et al. (1943) gave accounts of two such patients in whom $R h$ agglutinins were found.

There remains some uncertainty about the degree of risk of renal damage that is involved when a large amount of $\mathrm{Rh}$ positive blood is destroyed by incomplete anti- $D$ gammaglobulin. A cautious approach seems advisable at present, but it is likely that further experience in treating women with large transplacental haemorrhages will provide useful information.

\section{Summary}

Four Rh-negative women who had received large volumes of $\mathrm{Rh}$-positive blood were given incomplete anti-D in an attempt to prevent $\mathrm{Rh}$ immunization. Two were cases of transplacental haemorrhage and two received $\mathrm{Rh}$-incompatible transfusions. The patient given $27 \mathrm{ml}$. of anti-D-containing plasma developed anti-D. The other three patients did not develop anti-D. A mild haemolytic reaction occurred in the patient given anti-D in the form of $370 \mathrm{ml}$. of blood intravenously. No reactions 
were seen in the two patients receiving approximately $1,000 \mu \mathrm{g}$. of anti-D in the form of gammaglobulin intramuscularly.

The evidence suggests that $\mathrm{Rh}$ immunization by quite large transplacental haemorrhage can be safely prevented by giving anti-D gammaglobulin. A cautious approach to the use of this method in dealing with $\mathrm{Rh}$-incompatible transfusions in women before or during the child-bearing period seems justified.

We would like to thank Professor J. A. Stallworthy, Mr. C. H. de Boer, Mr. S. E. Riterband, and Dr. M. M. Pickles for permission to publish details of cases under their care. Dr. J. Darnborough carried out the serological investigations in Case 4 and Mr. W. T. A. Donohoe those in Case 1. We are indebted to Professor C. A. Clarke for his encouragement and advice in the preparation of this report. The gammaglobulin preparation of anti-D was provided by $\mathrm{Dr}$. D. Lehane in co-operation with $\mathrm{Dr}$.
W. d'A. Maycock and Mr. L. Vallet, of the Lister Institute for Preventive Medicine.

\section{REFERENCES}

Brit. med. F., 1966, 2, 907.

Clarke, C. A. (1967). Brit. med. 7., 4, 7.

Clarke, al. (1963). Ibid., 1, 979 .

Finn, R., Lehane, D., McConnell, R. B., Sheppard, P. M., and Woodrow, J. C. (1966). Ibid., 1, 213.

Finn, R., et al. (1961). Ibid., 1, 1486.

Freda, V. J., Gorman, J. G., and Pollack, W. (1964). Transfusion (Philad.), 4, 26.

Jandl, J. H., Jones, A. R., and Castle, W. B. (1957). J. clin. Invest., 36, 1428.

Kleihauer, E, and Betke, K. (1960). Internist (Berl.), 1, 292.

Mollison, P. L. (1967). Blood Transfusion in Clinical Medicine, 4th ed. Oxford.

Vogel, P., Rosenthal, N., and Levine, P. (1943). Amer. F. clin. Path.,

Woodrow, J. C. et al. (1965). Brit. med. F., 1, 279

\title{
Failure of a Relatively Small Dose of Passively Administered Anti-Rh to Suppress Primary Immunization by a Relatively Large Dose of Rh-positive Red Cells
}

\author{
N. C. HUGHES-JONES,* D.M., Ph.D. ; P. L. MOLliSON,* M.D., F.R.C.P., F.C.PATH.
}

Brit. med. F., 1968, 1, 150-151

Passively administered anti-Rh has been extraordinarily successful in suppressing primary immunization which would otherwise occur in certain $\mathrm{Rh}$-negative women after pregnancy. However, the amount of foetal red cells found in a mother's circulation after delivery is less than $1.5 \mathrm{ml}$. in $98 \%$ of cases (Clarke et al., 1966), and so far there is little experience of trying to suppress primary immunization when much larger amounts are involved, either as a result of transplacental haemorrhage or of inadvertent transfusion of $\mathrm{Rh}$-positive blood.

We here report two cases in which $\mathrm{Rh}$-negative patients received relatively large amounts of $\mathrm{Rh}$-positive red cells-in one case by transplacental haemorrhage and in the other by blood transfusion-and in which relatively small amounts of passively administered anti-Rh failed to prevent primary immunization.

\section{Case 1}

The patient. aged 26, gave birth to her first infant on 17 May 1967 ; she had not been pregnant before nor had she received a blood transfusion. The infant was very pale and appeared moribund; six hours after birth it was found to have a haemoglobin concentration of $6.3 \mathrm{~g} . / 100 \mathrm{ml}$. The mother was group $\mathrm{B} \mathrm{Rh}$ negative and the infant group B Rh-positive; the mother's serum did not contain anti-Rh and the infant's direct antiglobulin test was negative. A transplacental haemorrhage was suspected, and examination of the mother's blood by the acid-elution method showed numerous foetal red cells; from counts made in this laboratory it was estimated that approximately 1 in 36 of the red cells stained darkly. If it is assumed that the mother's red cell volume was $1,500 \mathrm{ml}$. and that the acid-elution method detects about $70 \%$ of the true number of foetal red cells present (unpublished observations) the volume of foetal red cells in the mother's circulation was approximately $60 \mathrm{ml}$.

The infant was given a blood transfusion and made a satisfactory recovery.

At about 60 hours after birth the mother was given an intramuscular injection of gammaglobulin (batch " $\mathrm{A}$ ") estimated to

- M.R.C. Experimental Haematology Research Unit, St. Mary's Hospital Medical School, London W.2. contain a total of $500 \mu \mathrm{g}$. of IgG anti-D ; the preparation contained no detectable agglutinating (IgM) anti-D. Estimates of the proportion of foetal cells present in the mother's blood were made at $2,3,6$, and 13 days after the injection of anti-D; the results are shown in Fig. 1. Half the cells disappeared in four to five days and all had gone by 13 days. Anti-D could be detected in the patient's plasma (indirect antiglobulin test) 48 hours after the injection, and it was still just detectable 20 days after the injection. A sample of serum taken from the mother seven weeks after the birth of the infant showed that anti-Rh was present to a titre of 2 ; five weeks later the titre was 16, and five weeks after this (four months after the birth of the infant) it was 32 .

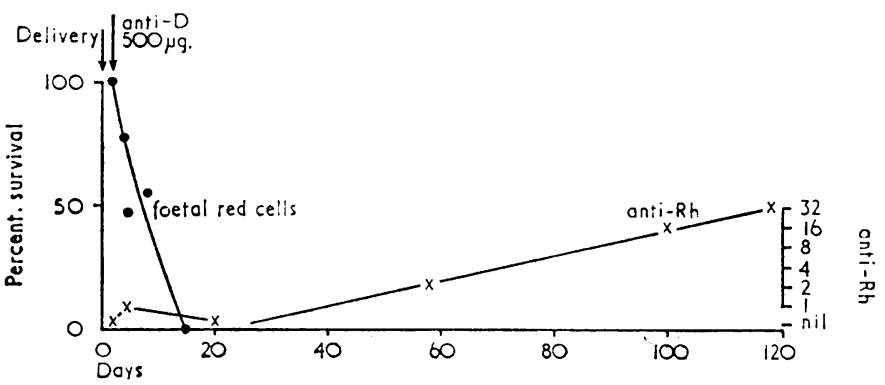

FIG. 1.-Case 1. Survival of foetal red cells in the mother's circulation and changes in the maternal anti- $\mathrm{Rh}$ titre.

\section{Case 2}

The patient, aged 21, had an abortion on 30 June 1967 . She was admitted to hospital next day because of considerable bleeding, and was transfused with two units of group $\mathrm{O} \mathrm{Rh}$-positive blood (containing a total of approximately $400 \mathrm{ml}$. of red cells) between the evening of 1 July and the morning of 2 July. It was then discovered that the patient was group $\mathrm{O} \mathrm{Rh}$-negative, and she was referred to us for treatment. On the evening of 3 July, 48 hours after the beginning of the blood transfusion, gammaglobulin (batch "B") containing $1,000 \mu \mathrm{g}$. of IgG anti-D was given intramuscularly; the preparation contained no agglutinating anti-D. Approximate estimates of the number of red cells present were made by incubating samples of the patient's blood with a potent anti-D, 